\title{
Soluble ST2 levels for predicting the presence and severity of metabolic syndrome
}

\author{
Xiao Zong ${ }^{1,2, *}$, Qin Fan ${ }^{1,2, *}$, Hang Zhang, ${ }^{1, *}$, Qian Yang ${ }^{1,2}$, Hongyang Xie ${ }^{1,2}$, Qiujing Chen ${ }^{2}$, Ruiyan Zhang ${ }^{1}$ and \\ Rong Tao'
}

1'Department of Vascular \& Cardiology, Ruijin Hospital, Shanghai Jiao Tong University School of Medicine, Shanghai, China

${ }^{2}$ Institution of Cardiovascular Diseases, Shanghai Jiao Tong University School of Medicine, Shanghai, China

Correspondence should be addressed to R Tao: rongtao@hotmail.com

*(X Zong, Q Fan and H Zhang contributed equally to this work)

\begin{abstract}
To explore the relationship between soluble ST2 (SST2) and metabolic syndrome (MetS) and determine whether SST2 levels can predict the presence and severity of MetS. We evaluated 550 consecutive subjects ( $58.91 \pm 9.69$ years, $50 \%$ male) with or without MetS from the Department of Vascular \& Cardiology, Shanghai Jiao Tong University-Affiliated Ruijin Hospital. Serum SST2 concentrations were measured. The participants were divided into three groups according to the SST2 tertiles. Univariate and multivariable logistic regression models were used to evaluate the association between serum SST2 concentrations and the presence of MetS. Serum SST2 concentrations were significantly higher in the MetS group than in those in the no MetS group (14.80 \pm 7.01 vs $11.58 \pm 6.41$ $\mathrm{ng} / \mathrm{mL}, P<0.01)$. Subjects with more MetS components showed higher levels of sST2. sST2 was associated with the occurrence of MetS after multivariable adjustment as a continuous log-transformed variable (per $1 \mathrm{SD}$, odds ratio (OR): 1.42, 95\% Cl: 1.13-1.80, $P<0.01$ ). Subgroup analysis showed that individuals with MetS have significantly higher levels of SST2 than those without MetS regardless of sex and age. High serum SST2 levels were significantly and independently associated with the presence and severity of MetS. Thus, sST2 levels may be a novel biomarker and clinical predictor of MetS.
\end{abstract}

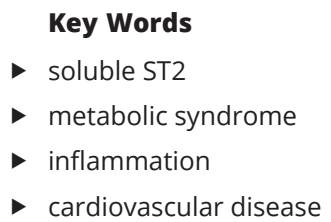

Endocrine Connections (2021) 10, 336-344

\section{Introduction}

Metabolic syndrome (MetS) is a constellation of metabolic abnormalities comprising central obesity, hypertension, diabetes mellitus (DM) or hyperglycemia, high triglyceride (TG) levels, and low levels of highdensity lipoprotein cholesterol (HDL-C) (1). The prevalence rate of MetS has markedly increased over the past decades due to obesity resulting from widespread overnutrition and an inactive lifestyle. The International Diabetes Federation estimates that MetS affects one-quarter of the world's adult population (2). Therefore, it has gradually become a major public health concern worldwide. MetS is also considered a chronic systemic inflammatory state and the main promoter of cardiovascular disease and multi-organ dysfunction (3, 4). However, there is limited data for predicting MetS and evaluating its severity.

Growth stimulation expressed gene 2 protein (ST2) was first discovered in 1989 (5) and its only known ligand is IL-33 (6). Two main isoforms of ST2 were found: a transmembrane full-length form (ST2L) and a soluble, secreted form (sST2) (7). The binding of ST2L and IL33 plays a protective role in cardiac stress $(8,9)$. However, sST2 acts as a decoy receptor of IL33 and inhibits IL33-ST2 signaling. SST2 has been identified as a promising biomarker of cardiovascular disease, especially in heart failure $(10,11,12,13)$.
This work is licensed under a Creative Commons Attribution-NonCommercial-NoDerivatives 4.0 Internationab ticense.ifica.com at $04 / 26 / 2023$ 08:46:24AM 
Increasing evidence shows that MetS shares a similar pathophysiological process with cardiovascular disease, including inflammation, hypertension, atherosclerosis, and insulin resistance (14). Thus, it is reasonable to consider that sST2 levels may be able to indicate early microenvironment abnormalities, such as MetS, that predate the onset of cardiovascular disease. Therefore, the present study aimed to explore the diagnostic and predictive value of sST2 levels for the occurrence of MetS and its severity.

\section{Materials and methods}

\section{Study design and population}

This cross-sectional study evaluated 550 consecutive subjects from the Department of Vascular \& Cardiology, Shanghai Jiao Tong University-Affiliated Ruijin Hospital, Shanghai, China. The inclusion criteria were older than 18 years with no coronary heart disease, heart failure, malignant tumor and autoimmune disease. The diagnosis of MetS was made after enrollment.

This study was approved by the institutional review committee of Ruijin Hospital (Ethics Committee reference number: 2016-019), and was conducted in accordance with the principles of the Helsinki Declaration. Written informed consent was obtained from all the participants in this study.

\section{Data collection and measures}

Baseline data, including medical history, health status, and family history, were obtained via face-to-face interviews. Height, weight, and waist circumference were measured using standard measurements. BMI was calculated using weight and height $\left(\mathrm{kg} / \mathrm{m}^{2}\right)$. Blood pressure was measured in the left arm using a calibrated aneroid sphygmomanometer, with the participant in a seated position after at least 5 min of rest.

Peripheral venous blood samples were collected and centrifuged at $1500 \mathrm{~g}$ at $4^{\circ} \mathrm{C}$ for $15 \mathrm{~min}$. The serum obtained by centrifugation was rapidly stored at $-80^{\circ} \mathrm{C}$. Echocardiography was conducted within 1 week from the collection of peripheral venous blood samples. Fasting plasma glucose, total cholesterol, TG, HDL-C, low-density lipoprotein cholesterol (LDL-C), and other routine biochemical parameters were measured using an automatic analyzer. Serum sST2 was measured using the venous serum samples via an ELISA Kit (DST200, R\&D) according to the manufacturer's protocol.

\section{Echocardiography}

All subjects underwent two-dimensional transthoracic echocardiography. After finding the standard long axial section of the left ventricle, M-mode echocardiography was used to measure the left ventricular end systolic diameter, left ventricular end diastolic diameter, left atrial diameter (LAD), aortic dimension, interventricular septal thickness (IVT), and left ventricular posterior wall thickness (LVPWT). Simpson's biplane method was used to measure left ventricular ejection fraction (LVEF).

\section{Definition of MetS}

The most widely accepted and clinically used definitions of MetS were established by the World Health Organization, National Cholesterol Education Program - Third Adult Treatment Panel (NCEP-ATPIII), and International Diabetes Federation. These three definitions differ only in detail. Here, we used the definition of NCEP-ATPIII for MetS, and waist circumference (WC) was adopted as a factor that is more suitable for the Chinese population. Criteria of MetS were as follows (15): (i) Central obesity: $W C \geq 90 \mathrm{~cm}$ in men or $\geq 80 \mathrm{~cm}$ in women; (ii) $\mathrm{TG} \geq 1.7 \mathrm{mmol} / \mathrm{L}$ or treatment of this lipid abnormality; (iii) HDL-C $<1.03 \mathrm{mmol} / \mathrm{L}$ in men or $<1.30 \mathrm{mmol} / \mathrm{L}$ in women; (iv) blood pressure $\geq 130 / 85$ $\mathrm{mmHg}$ or taking antihypertensive medications; and (v) fasting blood glucose $\geq 5.6 \mathrm{mmol} / \mathrm{L}$, previously diagnosed type $2 \mathrm{DM}$, or taking antidiabetic medications including oral antidiabetic agents or insulin. (Criteria for type $2 \mathrm{DM}$ : symptoms of diabetes + plasma glucose at any time $\geq 11.1$ $\mathrm{mmol} / \mathrm{L}$ or fasting plasma glucose $\geq 7.0 \mathrm{mmol} / \mathrm{L}$ or oral glucose tolerance test 2 - $\mathrm{h} \geq 11.1 \mathrm{mmol} / \mathrm{L}$.)

Specifically, subjects meeting three or more of the five criteria above were considered to have MetS while those meeting one or two or zero of the five criteria could be excluded from MetS diagnosis.

\section{Statistical analyses}

Continuous variables were presented as mean \pm s.D., whereas categorical variables were summarized as numbers and percentages. Variables with a skewed distribution were log-transformed to make them fit a normal distribution. Independent Student's $t$-test, one-way ANOVA test, the chi-square test and linear trend test were used to evaluate the differences among groups, as appropriate. Pearson correlation analysis was used to describe the correlations between sST2 levels and metabolic features.

This work is licensed under a Creative Commons Attribution-NonCommercial-NoDerivatives 4.0 Internationad bicense.ifica.com at 04/26/2023 08:46:24AM 
Subsequently, univariate and multivariable logistic regression models were used to evaluate the association between serum sST2 levels and the risk for MetS. For these models, we used (i) log-transformed sST2 level as a continuous variable analyzed per SD and (ii) tertiles of sST2 levels analyzed both as an ordinal variable and as categorical data. Subgroup analyses by age $(\geq 60 /<60$ years) and sex (male/female) were also conducted. All statistical tests were performed using IBM SPSS Statistics 22.0. A two-sided $P$-value of $<0.05$ was considered statistically significant.

\section{Results}

\section{Subject characteristics}

Overall, 275 (50.0\%) subjects were male. The mean age was $58.91 \pm 9.69$ years, and the mean sST2 level was $12.88 \pm 6.84 \mathrm{ng} / \mathrm{mL}$. The baseline subject characteristics are shown in Table 1 by tertiles of serum sST2 concentrations. There were trends across tertiles of higher levels of BMI, WC, systolic blood pressure, fasting glucose, glycosylated hemoglobin (HbA1c), and triglyceride levels, along with lower levels of HDL. In addition, subjects with higher sST2 levels had higher concentrations of white blood count, high-sensitivity C-reactive protein (hsCRP), and NT-proBNP, along with poorer liver and renal function. Among the subjects in the highest and lowest tertile of sST2, 59.0 and $43.2 \%$ were male, respectively. The LDL-C and LVEF levels were not significantly different among the patients in the three tertiles.

\section{sST2 levels were associated with the presence of MetS}

sST2 concentrations were significantly higher in the MetS group than that in the no MetS group (14.80 \pm 7.01 vs $11.58 \pm 6.41 \mathrm{ng} / \mathrm{mL}, \mathrm{P}<0.01$, Fig. 1A). Subjects with higher MetS scores (i.e. more components of MetS) showed higher levels of sST2 (Fig. 1B). As shown in Table 2, sST2 was associated with the presence of MetS after multivariable adjustment as a continuous logtransformed variable (per $1 \mathrm{SD}$, odds ratio (OR): 1.42, 95\% CI: 1.13-1.80, $P<0.01)$. Analysis of the tertiles of sST2 also showed that the adjusted risk of MetS was higher in subjects in the highest tertile than that in the subjects in the lowest tertile (OR: $2.52,95 \%$ CI: $1.45-4.39, P<0.01$, Ptrend <0.01).

\section{Subgroup analysis by age and sex}

Subgroup analysis showed that in both men and women and in subjects aged $<60$ years and $\geq 60$ years, MetS patients exhibited significantly higher levels of sST2 than those without MetS (Fig. 1C). Univariate and multivariable logistic regression analyses of the relationship between sST2 and MetS according to age and sex are shown in Table 3. After full adjustment, patients in the highest group of serum sST2 levels had significantly higher risk than those in the lowest group regardless of age and sex. Furthermore, as a continuous variable, sST2 retained significant predictive value particularly in the older group (adjusted OR: 1.83, 95\% CI: 1.31-2.56, $P<0.01$ ) and in men (adjusted OR: 1.80, 95\% CI: 1.29-2.49, $P<0.01$ ). This indicated that serum sST2 levels were independently associated with the risk for MetS in all subjects, especially in men and in subjects older than 60 years.

\section{Relationship between sST2 and MetS components}

We further analyzed the relationship between sST2 and each MetS component. Subjects with central obesity, hypertension, DM or hyperglycemia, hypertriglyceridemia, and lower HDL had significantly higher concentrations of serum sST2 than those without it (Fig. 2A). After adjustment for the full model including age, sex, BMI, alcohol use, smoking, and levels of creatinine, LDL-C, hsCRP, and NT-proBNP (model 3), the association between sST2 and each specific disease remained statistically significant (Fig. 2B and C). The ORs corresponding to a 1 S.D. increase of log-transformed sST2 level for the presence of hypertension, DM, hypertriglyceridemia, and lower HDL were 1.71 (95\% CI: 1.36-2.15, $P<0.01)$, 1.41 (95\% CI: $1.15-1.73, P<0.01), 1.27$ (95\% CI: $1.04-1.56, P=0.02)$, and 1.23 (95\% CI: 1.01-1.50, $P=0.04)$, respectively. Subjects in the highest level of sST2 had a significantly higher risk of meeting each diagnostic criterion of MetS than those in the lowest group, especially the blood pressure criteria (OR: 4.06, 95\% CI: 2.39-6.92, $P<0.01$ ).

\section{Discussion}

MetS shares a similar pathophysiological process with cardiovascular disease, and thus it is reasonable to consider that sST2 levels, as a novel biomarker of cardiovascular disease, may also be a biomarker of MetS. In this study, serum sST2 levels increased with an increase in the number of metabolic abnormalities.

This work is licensed under a Creative Commons Attribution-NonCommercial-NoDerivatives 4.0 International License.ifica com at 04/26/2023 08:46:24AM 
Table 1 Baseline characteristics of all subjected divided by serum levels of ST2.

\begin{tabular}{|c|}
\hline Number \\
\hline Age, years \\
\hline Male, sex \\
\hline $\mathrm{BMI}\left(\mathrm{kg} / \mathrm{m}^{2}\right)$ \\
\hline Waist circumference $(\mathrm{cm})$ \\
\hline Current smoking \\
\hline Alcohol use \\
\hline Systolic blood pressure (mmHg) \\
\hline Diastolic blood pressure (mmHg) \\
\hline Family history \\
\hline Medical history \\
\hline Hypertension \\
\hline Diabetes mellitus \\
\hline Dyslipidemia \\
\hline Laboratory measurements \\
\hline WBC $\left(\times 10^{9}\right)$ \\
\hline Hemoglobin (g/L) \\
\hline Platelet $\left(\times 10^{9}\right)$ \\
\hline Fasting glucose (mmol/L) \\
\hline $\mathrm{HbA} 1 \mathrm{c}(\%)$ \\
\hline ALT (IU/L) \\
\hline Albumin (g/L) \\
\hline Creatinine $(\mathrm{mmol} / \mathrm{L})$ \\
\hline $\operatorname{eGFR}^{\mathrm{MDRD}}\left(\mathrm{mL} / \mathrm{min} / 1.73 \mathrm{~m}^{2}\right)$ \\
\hline Uric acid $(\mu \mathrm{mol} / \mathrm{L})$ \\
\hline Triglyceride (mmol/L) \\
\hline Total cholesterol (mmol/L) \\
\hline LDL-C (mmol/L) \\
\hline HDL-C (mmol/L) \\
\hline D-dimer (mg/L) \\
\hline $\mathrm{hsCRP}(\mathrm{mg} / \mathrm{L})$ \\
\hline NTproBNP (pg/mL) \\
\hline Echocardiography parameters \\
\hline Aortic dimension (mm) \\
\hline LAD (mm) \\
\hline LVEDD (mm) \\
\hline LVESD (mm) \\
\hline IVT (mm) \\
\hline LVPWT (mm) \\
\hline LVEF (\%) \\
\hline
\end{tabular}

\begin{tabular}{|c|c|}
\hline$<8.97 \mathrm{ng} / \mathrm{mL}$ & $8.97-13.70 \mathrm{ng} / \mathrm{mL}$ \\
\hline 183 & 184 \\
\hline $56.74 \pm 9.00$ & $60.08 \pm 8.91$ \\
\hline 79 (43.2) & $88(47.8)$ \\
\hline $23.42 \pm 2.95$ & $24.28 \pm 3.64$ \\
\hline $80.00 \pm 9.94$ & $82.60 \pm 11.95$ \\
\hline $30(16.4)$ & $43(23.4)$ \\
\hline $19(10.4)$ & $28(15.2)$ \\
\hline $125.25 \pm 15.98$ & $129.67 \pm 18.55$ \\
\hline $75.31 \pm 10.29$ & $75.10 \pm 11.51$ \\
\hline $16(8.7)$ & $13(7.1)$ \\
\hline $44(24.0)$ & $81(44.0)$ \\
\hline $12(6.6)$ & $26(14.1)$ \\
\hline $1(0.5)$ & $9(4.9)$ \\
\hline $5.94 \pm 1.77$ & $6.43 \pm 2.01$ \\
\hline $131.92 \pm 15.18$ & $131.77 \pm 15.81$ \\
\hline $191.51 \pm 56.56$ & $187.83 \pm 60.94$ \\
\hline $5.01 \pm 0.91$ & $5.20 \pm 0.95$ \\
\hline $5.74 \pm 0.61$ & $5.93 \pm 0.79$ \\
\hline $24.15 \pm 21.97$ & $22.58 \pm 15.84$ \\
\hline $38.71 \pm 3.27$ & $38.66 \pm 3.41$ \\
\hline $74.68 \pm 17.83$ & $77.39 \pm 16.37$ \\
\hline $82.74 \pm 17.66$ & $80.48 \pm 22.03$ \\
\hline $302.45 \pm 80.47$ & $336.30 \pm 93.09$ \\
\hline $1.42 \pm 0.89$ & $1.69 \pm 1.10$ \\
\hline $4.42 \pm 0.88$ & $4.39 \pm 1.07$ \\
\hline $2.61 \pm 0.71$ & $2.58 \pm 0.91$ \\
\hline $1.24 \pm 0.37$ & $1.19 \pm 0.31$ \\
\hline $0.32 \pm 0.52$ & $0.49 \pm 1.34$ \\
\hline $2.05 \pm 2.22$ & $3.95 \pm 3.59$ \\
\hline $114.90 \pm 162.25$ & $165.17 \pm 213.96$ \\
\hline $32.51 \pm 3.05$ & $32.95 \pm 3.64$ \\
\hline $36.97 \pm 4.16$ & $38.36 \pm 4.38$ \\
\hline $47.40 \pm 4.29$ & $47.95 \pm 4.67$ \\
\hline $29.69 \pm 3.56$ & $30.10 \pm 3.88$ \\
\hline $9.12 \pm 1.28$ & $9.41 \pm 1.58$ \\
\hline $8.80 \pm 1.10$ & $9.01 \pm 1.36$ \\
\hline $66.81 \pm 4.80$ & $66.44 \pm 4.89$ \\
\hline
\end{tabular}

\begin{tabular}{c}
\hline $\mathbf{1 3 . 7 0} \mathbf{~ n g / m L}$ \\
\hline 183 \\
$59.89 \pm 10.74$ \\
$108(59.0)$ \\
$24.67 \pm 3.73$ \\
$84.55 \pm 13.20$ \\
$54(29.5)$ \\
$28(15.3)$ \\
$134.49 \pm 18.36$ \\
$76.52 \pm 12.21$ \\
$14(7.7)$
\end{tabular}

\begin{tabular}{rrr}
\hline \multicolumn{1}{rl}{$\boldsymbol{P}$ value } & & $\boldsymbol{P}$ for liner trend \\
\cline { 1 - 1 }$<0.01$ & & $<0.01$ \\
0.01 & & $<0.01$ \\
$<0.01$ & & $<0.01$ \\
$<0.01$ & & $<0.01$ \\
0.01 & & $<0.01$ \\
0.29 & & 0.17 \\
$<0.01$ & & $<0.01$ \\
0.44 & & 0.31 \\
0.19 & & 0.70
\end{tabular}

$110(60.1)$

$26(14.2)$

$14(7.7)$

$<0.01$

0.03

$<0.01$

$6.61 \pm 2.01$

$<0.01$

0.02

$35.07 \pm 16.74$

$<0.01$

$<0.01$

$187.62 \pm 61.64$

0.08

$<0.01$

$5.26 \pm 1.10$

$6.11 \pm 0.96$

$27.68 \pm 22.47$

0.78

0.04

$<0.01$

$38.57 \pm 4.05$

$81.48 \pm 20.51$

$79.47 \pm 21.01$

$355.21 \pm 106.11$

$1.81 \pm 1.30$

$4.23 \pm 1.06$

$2.52 \pm 0.83$

$1.08 \pm 0.30$

$0.43 \pm 0.69$

$4.80 \pm 3.76$

$186.86 \pm 272.67$

0.05

0.93

$<0.01$

0.29

$<0.01$

$<0.01$

0.02

0.58

$<0.01$

0.17

$<0.01$

0.01

0.06

0.53

0.02

$<0.01$

0.10

0.72

$<0.01$

0.13

$<0.01$

$<0.01$

0.07

0.30

$<0.01$

0.23

$<0.01$

$33.36 \pm 3.60$

$38.82 \pm 4.57$

$48.30 \pm 4.76$

$30.62 \pm 4.24$

$9.60 \pm 1.40$

$9.23 \pm 1.32$

$65.89 \pm 5.22$

$\begin{array}{r}0.06 \\ <0.01 \\ 0.17 \\ 0.07 \\ 0.01 \\ 0.01 \\ 0.21 \\ \hline\end{array}$

$<0.01$

0.02

$<0.01$

0.06

0.02

$<0.01$

$<0.01$

0.08

Data are presented as mean \pm s.D. or $n(\%)$.

ACEI, angiotensin-converting enzyme inhibitors; ALT, alanine aminotransferase; ARB, angiotensin receptor blockers; CCB, calcium channel blockers; eGFR, estimated glomerular filtration; HbA1C, glycated hemoglobin; HDL-C, high-density lipoprotein cholesterol; hsCRP, high sensitivity C reactive protein; IVT, interventricular septal thickness; LAD, left atrial diameter; LDL-C, low-density lipoprotein cholesterol; LVEDD, left ventricular end diastolic diameter; LVEF, left ventricular ejection fraction; LVESD, left ventricular end systolic diameter; LVPWT, left ventricular posterior wall thickness; NTproBNP, N-terminal pro-brain natriuretic peptide; WBC, white blood cell.

Univariate and multivariable logistic regression analyses demonstrated that high sST2 level was an independent risk factor for the presence of MetS, especially in men and in subjects older than 60 years. Thus, serum sST2 may be a biomarker for MetS. To our best knowledge, this study is the first to provide evidence on a correlation between serum sST2 levels and the presence and severity of MetS in the Chinese population.

Several studies have demonstrated that a continuous low-grade chronic systemic inflammatory state is an important pathophysiological feature of MetS, and some inflammatory factors are associated with it (16). Soluble ST2, as an important serum biomarker, has been shown to be involved in some inflammation-associated diseases. For example, during the acute exacerbation of idiopathic pulmonary fibrosis with the infiltration of inflammatory cells in the lungs, the serum levels of sST2 significantly increased with the development of inflammation (17). Serum sST2 levels were also found to be higher in asthma, which is a typical inflammatory disease, and was strongly

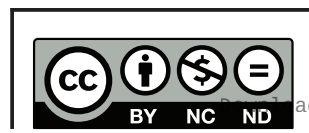

This work is licensed under a Creative Commons Attribution-NonCommercial-NoDerivatives 4.0 International License.ifica, com at $04 / 26 / 2023 \quad 08: 46: 24 \mathrm{AM}$ 
A

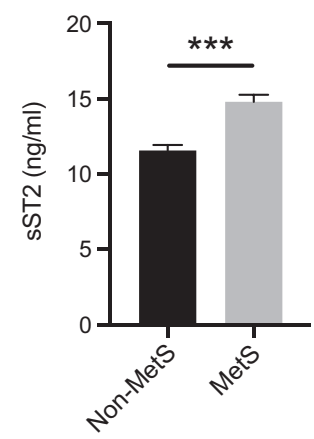

B

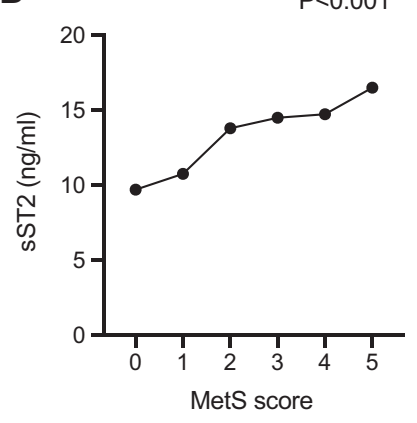

C

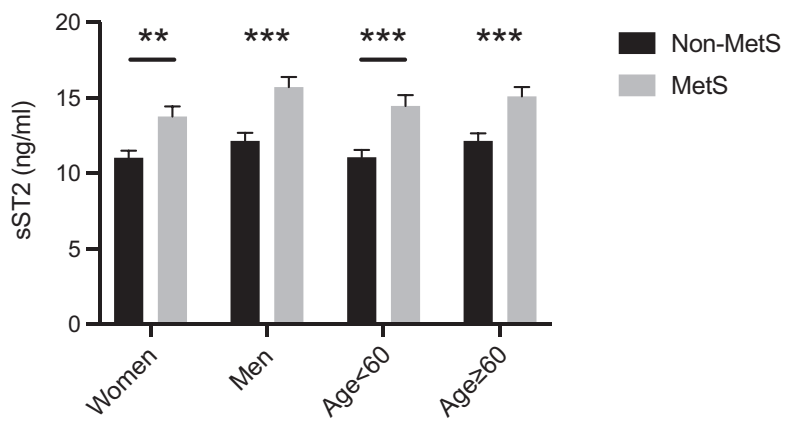

Figure 1

Expression of serum soluble ST2 (SST2) levels in the different groups. (A) Comparison of sST2 expression between the metabolic syndrome (MetS) group and the no MetS group. (B) Correlation analysis between SST2 levels and the number of MetS components. (C) SST2 expression by age group ( $<60$ years and $\geq 60$ years) and sex (male and female). ${ }^{*} P<0.05$, $\star \star P<0.01, * \star \star P<0.001$.

correlated with the severity of asthma exacerbation (18). However, unlike the above single-system inflammationassociated diseases, inflammation in MetS arise from adipocytes, macrophages, and impaired endothelial cells and involves multiple systems and metabolic processes throughout the body (16).

sST2 was found to be associated with the inflammatory process of several cells, tissues, and organs (19). In this study, we observed a consistent increase in SST2 and hsCRP, which is considered a sensitive marker of inflammation.
Thus, we speculated that sST2 could indicate the inflammation level in patients with MetS, in many ways influencing multiple aspects. Further, we found high sST2 levels in patients with central obesity. Monocyte-derived macrophages residing in adipose tissue can secrete various proinflammatory factors such as tumor necrosis factor- $\alpha$, interleukin-6, and interleukin-1. Therefore, obesity itself is a state of inflammation, which may be reflected or influenced by sST2. Moreover, hypertension, DM, and dyslipidemia are also regarded as chronic inflammation processes involving multiple organs $(20,21,22)$. ST2 itself may participate in the pathophysiological process of each component of MetS by affecting the inflammatory and immune response, thus taking part in the occurrence and development of MetS as well as reflecting its severity.

It is generally believed that SST2 functions through the IL33-ST2 axis, that is, it binds to IL33 as bait and blocks IL33 activation of downstream signaling pathways. However, whether the IL33-ST2 axis confers pro- or antiinflammation effects depends on the disease type. For example, in an ovalbumin-induced murine model of asthma, ST2-deficient mice developed attenuated airway inflammation and IL-5 production. Meanwhile, IL-33 administration exacerbated airway inflammation in wild-type mice (23). In another inflammation-associated disease, IL-33 treatment lowered the development of atherosclerosis and macrophage accumulation in $\mathrm{ApoE}^{-1-}$ mice fed with a high-fat diet. This effect can be blocked by SST2, thus leading to a larger atherosclerosis plaque (24). This characteristic may be due to the activation of different downstream pathways. The inflammatory process in MetS involves multiple organs and systems. Therefore, the role of sST2 in MetS may not be simply summarized as proinflammatory or anti-inflammatory, despite its relationship with disease severity. As such, further studies are warranted.

Each component of MetS has the potential to affect the endothelium and cause vascular dysfunction or disrupt vascular homeostasis. In turn, endothelial

Table 2 Univariate and multivariable logistic regression analysis for MetS in all subjects.

\begin{tabular}{|c|c|c|c|c|c|c|}
\hline & Unadjusted OR & P value & Adjusted OR for model 1 & P value & Adjusted OR for model 2 & P value \\
\hline Log ST2 per S.D. & $1.75(1.45-2.11)$ & $<0.01$ & $1.67(1.35-2.07)$ & $<0.01$ & $1.42(1.13-1.80)$ & $<0.01$ \\
\hline ST2 tertiles & $2.01(1.61-2.51)$ & $<0.01$ & $1.88(1.47-2.42)$ & $<0.01$ & $1.58(1.20-2.08)$ & $<0.01$ \\
\hline Tertile 1 & 1 (ref) & & 1 (ref) & & 1 (ref) & \\
\hline Tertile 2 & $2.53(1.61-3.97)$ & $<0.01$ & $2.23(1.35-3.68)$ & $<0.01$ & $1.68(0.98-2.89)$ & 0.06 \\
\hline Tertile 3 & $4.14(2.63-6.49)$ & $<0.01$ & $3.58(2.16-5.93)$ & $<0.01$ & $2.52(1.45-4.39)$ & $<0.01$ \\
\hline
\end{tabular}

Model 1: adjusted for age, gender and BMI. Model 2: adjusted for age, gender, BMI, alcohol use, smoke, creatinine, LDL-C, hsCRP and NTproBNP. Continuous variables were entered per $1 \mathrm{SD}$.

hsCRP, high sensitivity C reactive protein; LDL-C, low-density lipoprotein cholesterol; MetS, metabolic syndrome; NTproBNP, N-terminal pro-brain natriuretic peptide; OR, odds ratio.

https://ec.bioscientifica.com https://doi.org/10.1530/EC-20-0645 (c) 2021 The authors Published by Bioscientifica Ltd

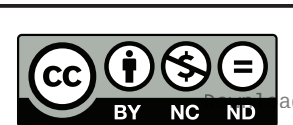

This work is licensed under a Creative Commons Attribution-NonCommercial-NoDerivatives 4.0 elnternationab ficense.ifica com at $04 / 26 / 2023$ 08:46:24AM 
Table 3 Univariate and multivariable logistic regression analysis for MetS in subjected divided by age and gender.

\begin{tabular}{l}
\hline \\
\cline { 1 - 2 } Age $<60$ years \\
Log ST2 per S.D. \\
ST2 tertiles \\
Tertile 1 \\
Tertile 2 \\
Tertile 3 \\
Age $\geq 60$ years \\
Log ST2 per S.D. \\
Tertiles \\
Tertile 1 \\
Tertile 2 \\
Tertile 3 \\
Women \\
Log ST2 per S.D. \\
Tertiles \\
Tertile 1 \\
Tertile 2 \\
Tertile 3 \\
Men \\
Log ST2 per S.D. \\
Tertiles \\
Tertile 1 \\
Tertile 2 \\
Tertile 3 \\
\hline
\end{tabular}

\begin{tabular}{|c|c|}
\hline Unadjusted OR & $P$ value \\
\hline $1.74(1.35-2.25)$ & $<0.01$ \\
\hline $2.13(1.57-2.90)$ & $<0.01$ \\
\hline \multicolumn{2}{|l|}{1 (ref) } \\
\hline $3.12(1.66-5.84)$ & $<0.01$ \\
\hline $4.59(2.46-8.54)$ & $<0.01$ \\
\hline $1.75(1.32-2.32)$ & $<0.01$ \\
\hline $1.87(1.35-2.59)$ & $<0.01$ \\
\hline \multicolumn{2}{|l|}{1 (ref) } \\
\hline $1.99(1.02-3.87)$ & 0.05 \\
\hline $3.55(1.82-6.91)$ & $<0.01$ \\
\hline $1.64(1.26-2.13)$ & $<0.01$ \\
\hline $1.90(1.39-2.61)$ & 0.01 \\
\hline \multicolumn{2}{|l|}{1 (ref) } \\
\hline $3.58(1.93-6.63)$ & $<0.01$ \\
\hline $3.63(1.89-6.97)$ & $<0.01$ \\
\hline $1.86(1.41-2.45)$ & $<0.01$ \\
\hline $2.12(1.54-2.91)$ & $<0.01$ \\
\hline 1 (ref) & \\
\hline $1.69(0.87-3.29)$ & 0.13 \\
\hline $4.29(2.27-8.11)$ & $<0.01$ \\
\hline
\end{tabular}

\begin{tabular}{c}
\hline Adjusted OR for model 1 \\
\hline $1.62(1.21-2.17)$ \\
$1.99(1.40-2.82)$ \\
1 (ref) \\
$2.86(1.40-5.83)$ \\
$3.93(1.94-7.98)$ \\
$1.83(1.32-2.54)$ \\
$1.80(1.25-2.60)$ \\
1 (ref) \\
$1.70(0.82-3.52)$ \\
$3.22(1.54-6.74)$ \\
$1.58(1.19-2.10)$ \\
$1.86(1.31-2.64)$ \\
1 (ref) \\
$3.06(1.57-5.96)$ \\
$3.41(1.68-6.93)$ \\
$1.87(1.35-2.58)$ \\
$1.98(1.36-2.87)$ \\
1 (ref) \\
$1.69(0.77-3.73)$ \\
$4.08(1.90-8.77)$ \\
\hline
\end{tabular}

\begin{aligned} \hline P value \\ \hline$<0.01 \\ <0.01 \\ <0.01 \\ <0.01 \\ <0.01 \\ <0.01 \\ \\ 0.15 \\ <0.01 \\ <0.01 \\ <0.01 \\ <0.01 \\ <0.01 \\ <0.01 \\ <0.01 \\ 0.19 \\ <0.01\end{aligned}$

\begin{tabular}{cccc}
\hline Adjusted OR for model $\mathbf{2}$ & & P value \\
\cline { 1 - 1 } $1.28(0.94-1.76)$ & & 0.12 \\
$1.52(1.04-2.24)$ & & 0.03 \\
$1($ ref $)$ & & \\
$1.96(0.90-4.23)$ & & 0.09 \\
$2.36(1.09-5.12)$ & & 0.03 \\
& & \\
$1.83(1.31-2.56)$ & & $<0.01$ \\
$1.87(1.28-2.75)$ & & $<0.01$ \\
$1($ ref $)$ & & \\
$1.67(0.79-3.54)$ & & 0.18 \\
$3.45(1.60-7.44)$ & & $<0.01$ \\
$1.25(0.92-1.70)$ & & 0.16 \\
$1.45(1.00-2.12)$ & & 0.05 \\
$1($ ref $)$ & & \\
$2.20(1.08-4.48)$ & & 0.03 \\
$2.12(1.00-4.59)$ & & 0.05 \\
$1.80(1.29-2.49)$ & $<0.01$ \\
$1.91(1.31-2.78)$ & $<0.01$ \\
$1($ ref $)$ & \\
$1.46(0.66-3.24)$ & 0.35 \\
$3.49(1.63-7.44)$ & $<0.01$ \\
\hline
\end{tabular}

Model 1: adjusted for age, gender and BMI. Model 2: adjusted for age, gender, BMI, alcohol use, smoke, creatinine, LDL-C, hsCRP and NTproBNP. Continuous variables were entered per 1 S.D.

hsCRP, high sensitivity C reactive protein; LDL-C, low-density lipoprotein cholesterol; MetS, metabolic syndrome; NTproBNP, N-terminal pro-brain natriuretic peptide; OR, odds ratio.

dysfunction can aggravate MetS. Vascular dysfunction is a key contributor to the pathogenesis of MetS. Our research shows that sST2 is strongly correlated with high systolic blood pressure but not diastolic blood pressure, consistent with the findings of a previous study (25). This result indicates that SST2 may correlate with vascular stiffness and compliance. Both ST2 and IL-33 are expressed and act in human endothelial cells $(26,27)$. As such, sST2, which is derived from ST2 and interacts with IL-33, may also play an important role in vascular biology.

Furthermore, the excessive production of reactive oxygen species (ROS) is another reason for endothelial dysfunction and metabolic disorders in MetS $(28,29)$. Fat cell and macrophage accumulation can increase ROS production and fatty acid concentration during hyperlipidemia. This in turn inhibits the efficiency of oxidative phosphorylation, and the production of ROS also increases sharply. Excessive ROS can oxidize various lipid components, such as oxidized LDL, which plays an important role in endothelial dysfunction and the development of MetS. Studies have shown that ROS can activate the IL33/ST2 axis and promote the release of IL33, which can in turn inhibit ROS production $(8,30)$.
Therefore, the ST2-IL33 axis plays a protective role in endothelial dysfunction caused by oxidative stress, while sST2 functions in the opposite direction.

Abnormal glucose and lipid metabolism is an important characteristic of MetS. Studies have shown that SST2 is associated with glucose and lipid metabolism. In type 2 diabetes patients with normal blood glucose tolerance, circulating sST2 levels were significantly higher and were significantly associated with fasting blood glucose and HbA1c (31). Bariatric surgery in severely obese diabetes patients improves metabolic status, and circulating sST2 levels decrease with improvements in liver function and lipid metabolism markers (32). In line with these findings, we found that sST2 is correlated with DM and dyslipidemia. The liver is the main organ for glucolipid metabolism, and we also observed worse liver function in patients with the highest sST2 tertile. However, the role of the IL33-ST2 pathway in liver metabolism remains controversial $(33,34)$, and the involvement of sST2 in glucose and lipid metabolism abnormalities needs to be further studied.

On the other hand, our present study demonstrated that SST2 levels were associated with cardiac hypertrophy, 
A

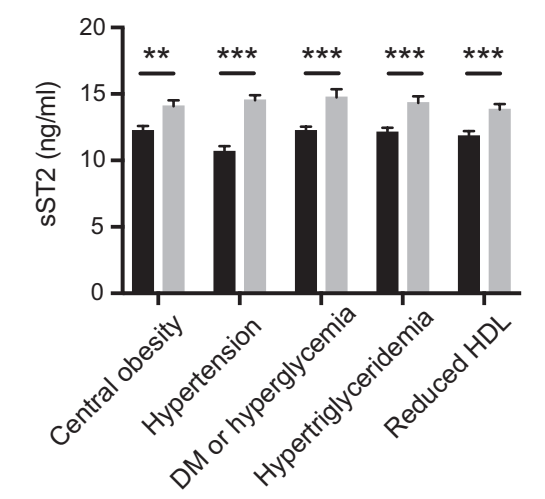

B

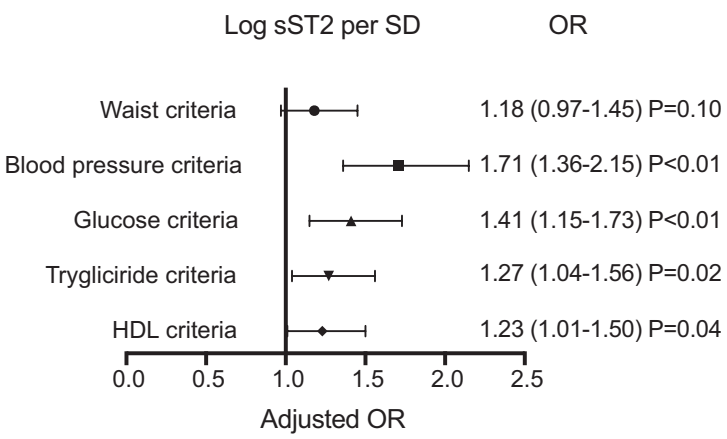

C

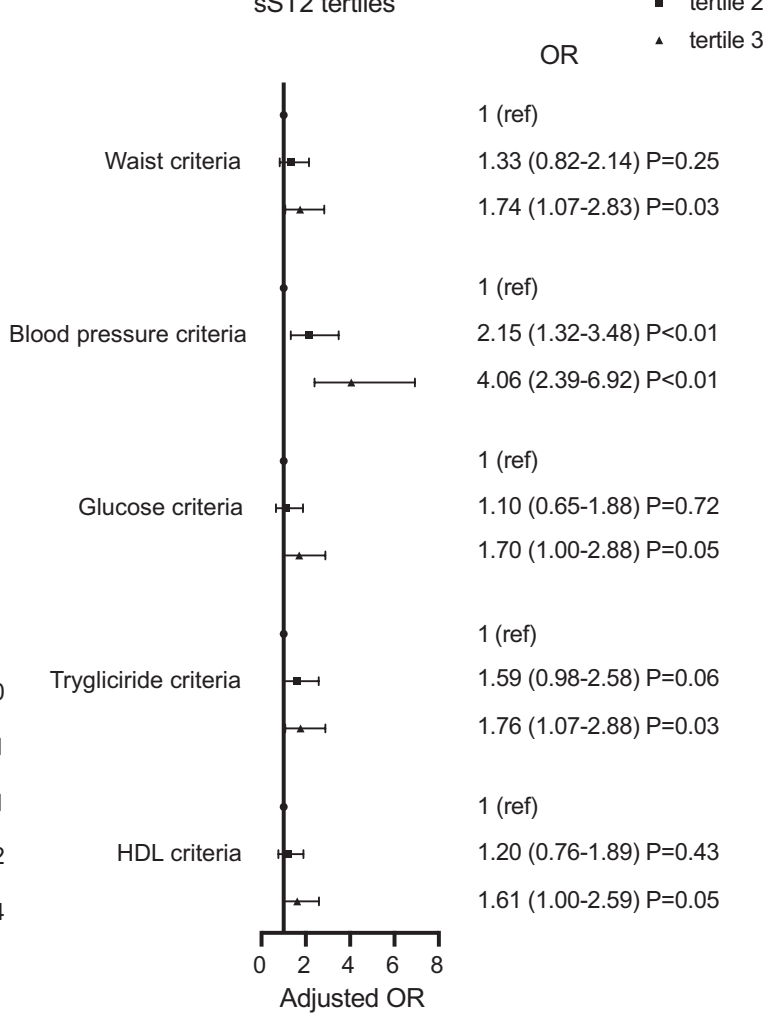

Figure 2

Relationship between soluble ST2 (sST2) and the components of metabolic syndrome (MetS). (A) Serum sST2 levels were compared between patients grouped by individual MetS components. (B) Full model Logistic regression for log-transformed sST2 and each component of MetS. (C) Full model logistic regression for SST2 tertiles and each component of MetS. ${ }^{*} P<0.05, * \star P<0.01, * \star \star P<0.001$ (age, sex, BMI, alcohol use, smoking, and levels of creatinine, LDL-C, hsCRP, and NT-proBNP were adjusted).

as indicated by the relationship of sST2 with LAD, IVT and LVPWT, which is in accordance with another study of patients with MetS (35). However, cardiac hypertrophy may only be a secondary outcome of hypertension and inflammation, so evidence for a direct link between sST2 and cardiac hypertrophy is lacking.

\section{Limitations}

This study has some limitations. First, it is a smallscale and single-center study. Therefore, we could not completely avoid the influence of confounding factors on our findings. Second, we did not detect the serum level of IL-33, and thus it is unclear whether sST2 functions through IL33. Third, because of the cross-sectional design, we cannot determine the causal relationship between MetS and SST2, thus needing further investigation, especially basic experiments. Moreover, studies with a larger sample size are needed to validate the diagnostic value of sST2 levels in MetS.

\section{Conclusion}

The present study found that high serum SST2 levels were significantly and independently associated with the presence and severity of MetS. Subjects with more MetS components showed higher levels of sST2. Thus, sST2 levels may be a novel biomarker of MetS.

\section{Declaration of interest}

The authors declare that there is no conflict of interest that could be perceived as prejudicing the impartiality of the research reported.

\section{Funding}

This study was supported by the National Nature Science Foundation of China (81670352 and 81970327 to R T, 82000368 to Q F).

\section{Acknowledgement}

The authors would like to thank all the enrolled subjects for their patience and understanding. 


\section{References}

1 Eckel RH, Grundy SM \& Zimmet PZ. The metabolic syndrome. Lancet 2005365 1415-1428. (https://doi.org/10.1016/S01406736(05)66378-7)

2 Alberti G, Zimmet P \& Shaw J. Metabolic syndrome - a new world-wide definition. A Consensus Statement from the International Diabetes Federation. Diabetes Medicine 200623 469-480. (http://doi.org/10.1111/j.1464-5491.2006.01858.x)

3 Lin YH, Zhang RC, Hou LB, Wang KJ, Ye ZN, Huang T, Zhang J, Chen X \& Kang JS. Distribution and clinical association of plasma soluble ST2 during the development of type 2 diabetes. Diabetes Research and Clinical Practice 2016118 140-145. (https://doi. org/10.1016/j.diabres.2016.06.006)

4 Malik S, Wong ND, Franklin SS, Kamath TV, L'Italien GJ, Pio JR \& Williams GR. Impact of the metabolic syndrome on mortality from coronary heart disease, cardiovascular disease, and all causes in United States adults. Circulation 2004110 1245-1250. (https://doi. org/10.1161/01.CIR.0000140677.20606.0E)

5 Klemenz R, Hoffmann S \& Werenskiold AK. Serum- and oncoproteinmediated induction of a gene with sequence similarity to the gene encoding carcinoembryonic antigen. PNAS 198986 5708-5712. (https://doi.org/10.1073/pnas.86.15.5708)

6 Schmitz J, Owyang A, Oldham E, Song Y, Murphy E, McClanahan TK, Zurawski G, Moshrefi M, Qin J, Li X, et al. IL-33, an interleukin-1-like cytokine that signals via the IL-1 receptorrelated protein ST2 and induces T helper type 2-associated cytokines. Immunity 200523 479-490. (https://doi.org/10.1016/j. immuni.2005.09.015)

7 Bergers G, Reikerstorfer A, Braselmann S, Graninger P \& Busslinger M. Alternative promoter usage of the Fos-responsive gene Fit-1 generates mRNA isoforms coding for either secreted or membrane-bound proteins related to the IL-1 receptor. EMBO Journal 1994131176 1188. (https://doi.org/10.1002/j.1460-2075.1994.tb06367.x)

8 Sanada S, Hakuno D, Higgins LJ, Schreiter ER, McKenzie AN \& Lee RT. IL-33 and ST2 comprise a critical biomechanically induced and cardioprotective signaling system. Journal of Clinical Investigation 2007117 1538-1549. (https://doi.org/10.1172/JCI30634)

9 Seki K, Sanada S, Kudinova AY, Steinhauser ML, Handa V, Gannon J \& Lee RT. Interleukin-33 prevents apoptosis and improves survival after experimental myocardial infarction through ST2 signaling. Circulation: Heart Failure 20092 684-691. (https://doi.org/10.1161/ CIRCHEARTFAILURE.109.873240)

10 Weinberg EO, Shimpo M, Hurwitz S, Tominaga S, Rouleau JL \& Lee RT. Identification of serum soluble ST2 receptor as a novel heart failure biomarker. Circulation 2003107 721-726. (https://doi. org/10.1161/01.cir.0000047274.66749.fe)

11 Aimo A, Vergaro G, Passino C, Ripoli A, Ky B, Miller WL, BayesGenis A, Anand I, Januzzi JL \& Emdin M. Prognostic value of soluble suppression of tumorigenicity- 2 in chronic heart failure: a meta-analysis. JACC: Heart Failure 20175 280-286. (https://doi. org/10.1016/j.jchf.2016.09.010)

12 Aimo A, Vergaro G, Ripoli A, Bayes-Genis A, Pascual Figal DA, de Boer RA, Lassus J, Mebazaa A, Gayat E, Breidthardt T, et al. Metaanalysis of soluble suppression of tumorigenicity-2 and prognosis in acute heart failure. JACC: Heart Failure 20175 287-296. (https://doi. org/10.1016/j.jchf.2016.12.016)

13 Shimpo M, Morrow DA, Weinberg EO, Sabatine MS, Murphy SA, Antman EM \& Lee RT. Serum levels of the interleukin-1 receptor family member ST2 predict mortality and clinical outcome in acute myocardial infarction. Circulation 2004109 2186-2190. (https://doi. org/10.1161/01.CIR.0000127958.21003.5A)

14 Tune JD, Goodwill AG, Sassoon DJ \& Mather KJ. Cardiovascular consequences of metabolic syndrome. Translational Research 2017 183 57-70. (https://doi.org/10.1016/j.trsl.2017.01.001)
15 Grundy SM, Cleeman JI, Daniels SR, Donato KA, Eckel RH, Franklin BA, Gordon DJ, Krauss RM, Savage PJ, Smith Jr SC, et al. Diagnosis and management of the metabolic syndrome: an American Heart Association/National Heart, Lung, and Blood Institute Scientific Statement. Circulation 2005112 2735-2752. (https://doi. org/10.1161/CIRCULATIONAHA.105.169404)

16 Sutherland JP, Mckinley B \& Eckel RH. The metabolic syndrome and inflammation. Metabolic Syndrome and Related Disorders 20042 82-104. (https://doi.org/10.1089/met.2004.2.82)

17 Tajima S, Oshikawa K, Tominaga S \& Sugiyama Y. The increase in serum soluble ST2 protein upon acute exacerbation of idiopathic pulmonary fibrosis. Chest 2003124 1206-1214. (https://doi. org/10.1378/chest.124.4.1206)

18 Watanabe M, Nakamoto K, Inui T, Sada M, Honda K, Tamura M, Ogawa Y, Yokoyama T, Saraya T, Kurai D, et al. Serum sST2 levels predict severe exacerbation of asthma. Respiratory Research 201819 169. (https://doi.org/10.1186/s12931-018-0872-2)

19 Griesenauer B \& Paczesny S. The ST2/IL-33 axis in immune cells during inflammatory diseases. Frontiers in Immunology 20178475. (https://doi.org/10.3389/fimmu.2017.00475)

20 McCarthy CG, Goulopoulou S \& Webb RC. Paying the toll for inflammation. Hypertension 201973 514-521. (https://doi. org/10.1161/HYPERTENSIONAHA.118.11782)

21 Oguntibeju OO. Type 2 diabetes mellitus, oxidative stress and inflammation-examining the links. International Journal of Physiology, Pathophysiology and Pharmacology 201911 45-63.

22 Libby P. Inflammation in atherosclerosis. Nature 2002420 868-874. (https://doi.org/10.1038/nature01323)

23 Kurowska-Stolarska M, Kewin P, Murphy G, Russo RC, Stolarski B, Garcia CC, Komai-Koma M, Pitman N, Li Y, Niedbala W, et al. IL-33 induces antigen-specific IL-5+ T cells and promotes allergic-induced airway inflammation independent of IL-4. Journal of Immunology 2008 181 4780-4790. (https://doi.org/10.4049/jimmunol.181.7.4780)

24 Miller AM, Xu D, Asquith DL, Denby L, Li Y, Sattar N, Baker AH, McInnes IB \& Liew FY. IL-33 reduces the development of atherosclerosis. Journal of Experimental Medicine 2008205 339-346. (https://doi.org/10.1084/jem.20071868)

25 Ho JE, Larson MG, Ghorbani A, Cheng S, Vasan RS, Wang TJ \& Januzzi Jr JL. Soluble ST2 predicts elevated SBP in the community. Journal of Hypertension 201331 1431-1436; discussion 1436. (https:// doi.org/10.1097/HJH.0b013e3283611bdf)

26 Moussion C, Ortega N \& Girard JP. The IL-1-like cytokine IL-33 is constitutively expressed in the nucleus of endothelial cells and epithelial cells in vivo: a novel 'alarmin'? PLOS ONE 20083 e3331. (https://doi.org/10.1371/journal.pone.0003331)

27 Bartunek J, Delrue L, Van Durme F, Muller O, Casselman F, De Wiest B, Croes R, Verstreken S, Goethals M, de Raedt H, et al. Nonmyocardial production of ST2 protein in human hypertrophy and failure is related to diastolic load. Journal of the American College of Cardiology 200852 2166-2174. (https://doi.org/10.1016/j. jacc.2008.09.027)

28 Chinen I, Shimabukuro M, Yamakawa K, Higa N, Matsuzaki T, Noguchi K, Ueda S, Sakanashi M \& Takasu N. Vascular lipotoxicity: endothelial dysfunction via fatty-acid-induced reactive oxygen species overproduction in obese Zucker diabetic fatty rats. Endocrinology 2007148 160-165. (https://doi.org/10.1210/en.20061132)

29 Tang EH \& Vanhoutte PM. Endothelial dysfunction: a strategic target in the treatment of hypertension? Pflugers Archiv 2010459 995-1004. (https://doi.org/10.1007/s00424-010-0786-4)

30 Uchida M, Anderson EL, Squillace DL, Patil N, Maniak PJ, Iijima K, Kita H \& O'Grady SM. Oxidative stress serves as a key checkpoint for IL-33 release by airway epithelium. Allergy 201772 1521-1531. (https://doi.org/10.1111/all.13158)

31 Cardellini M, Rizza S, Casagrande V, Cardolini I, Ballanti M, Davato F, Porzio O, Canale MP, Legramante JM, Mavilio M, et al. Soluble ST2 is

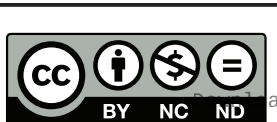

This work is licensed under a Creative Commons Attribution-NonCommercial-NoDerivatives 4.0 Internationab ficense ifica com at $04 / 26 / 2023$ 08:46:24AM 
a biomarker for cardiovascular mortality related to abnormal glucose metabolism in high-risk subjects. Acta Diabetologica 201956 273-280. (https://doi.org/10.1007/s00592-018-1230-z)

32 Demyanets S, Kaun C, Kaider A, Speidl W, Prager M, Oravec S, Hohensinner P, Wojta J \& Rega-Kaun G. The pro-inflammatory marker soluble suppression of tumorigenicity-2 (ST2) is reduced especially in diabetic morbidly obese patients undergoing bariatric surgery. Cardiovascular Diabetology 202019 26. (https://doi. org/10.1186/s12933-020-01001-y)

33 Pejnovic N, Jeftic I, Jovicic N, Arsenijevic N \& Lukic ML. Galectin-3 and IL-33/ST2 axis roles and interplay in diet-induced steatohepatitis. World Journal of Gastroenterology 201622 9706-9717. (https://doi.org/10.3748/wjg.v22.i44.9706)

34 Gao Y, Liu Y, Yang M, Guo X, Zhang M, Li H, Li J \& Zhao J. IL-33 treatment attenuated diet-induced hepatic steatosis but aggravated hepatic fibrosis. Oncotarget 20167 33649-33661. (https://doi. org/10.18632/oncotarget.9259)

35 Celic V, Majstorovic A, Pencic-Popovic B, Sljivic A, Lopez-Andres N, Roy I, Escribano E, Beunza M, Melero A, Floridi F, et al. Soluble ST2 levels and left ventricular structure and function in patients with metabolic syndrome. Annals of Laboratory Medicine 201636 542-549. (https://doi.org/10.3343/alm.2016.36.6.542)

Received in final form 22 December 2020

Accepted 10 February 2021

Accepted Manuscript published online 19 February 2021 (c) 2021 The authors Published by Bioscientifica Ltd
This work is licensed under a Creative Commons Attribution-NonCommercial-NoDerivatives 4.0 Internationad dicense ifica. com at 04/26/2023 08:46:24AM 